trolled studies have suggested that these risks may be reduced after myocardial revascularisation $^{25}$ and, although lung resection and coronary artery surgery have been performed successfully as combined procedures, ${ }^{6}$ it has been argued that vein graft surgery should be performed before lung resection. ${ }^{12}$

Cardiac surgery could not be performed as the initial procedure in our patient because anticoagulation would have led to uncontrollable bleeding from the haemorrhagic tumour, and obstruction of the left main bronchus might have predisposed him to pneumonia and would have compounded the loss of respiratory reserve that is known to occur after coronary artery surgery. ${ }^{7}$ This latter problem was apparent when the left main bronchus became temporarily obstructed by a fibrin plug. Despite this complication, laser therapy was judged to have been successful in minimising these risks. Bleeding did not occur during cardiac surgery and resection of the tumour ensured a rapid recovery of ventilatory function after removal of the fibrin plug.

Ideally, pneumonectomy would have been performed shortly after coronary artery surgery. The risk of transferring methicillin resistant Staphylococcus aureus, however, was considered to outweigh the risk of tumour spread. Metastatic disease was not evident at the time of surgery and our patient's predicted five year survival is $40 \%{ }^{4}$

Although endoscopic laser resection has been developed as a palliative treatment, there are now several reports on its value before thoracotomy in patients with operable tumours of the upper airway who presented with impen- ding asphyxia. ${ }^{8-10}$ In these cases the laser restored an adequate airway and thereby provided time in which to plan elective surgery. Our experience shows how laser therapy may also be used to optimise a patient's fitness for cardiac surgery and so facilitate the most appropriate sequence of operative procedures.

We are most grateful to Sister Ophelia Tsang for her assistance with endoscopic laser therapy.

1 Peters RM, Swain JA. Management of a patient with emphysema, coronary artery disease, and lung cancer. $A m$ J Surg 1982;143:701-5.

2 Foster ED, Davis KB, Carpenter JA, Abele S, Fray D. Risk of noncardiac operation in patients with defined coronary disease: the coronary artery surgery study (CASS) registr experience. Ann Thorac Surg 1986;41:42-9.

3 George PJM, Pattison J, Al Jarad N, Tsang O, Whitburn RH, Goldhill DR, et al. Preliminary experience with the $1.32 \mu \mathrm{m}$ neodymium YAG laser in the treatment of tracheobronchial malignancy. Lasers in Medical Science 1991;6:407-13.

4 Mountain CF. A new international staging system for lung cancer. Chest 1986;89(suppl):225-33S.

5 Crawford ES, Morris GC, Howell JF, Flynn WF, Moorhead DT. Operative risk in patients with previous coronary artery bypass. Ann Thorac Surg 1978;26:215-20.

6 Dalton MI, Parker TM, Mistrot J, Bricker DL. Concomitant coronary artery bypass surgery and major noncardiac surgery. J Thorac Cardiovasc Surg 1978;75: 621-31.

7 Jenkins SC, Soutar SA, Forsyth A, Keates JRW, Moxham J. Lung function after coronary artery surgery using the internal mammary artery and the long saphenous vein. Thorax 1989;44:209-11.

8 Laforet EG, Berger RL, Vaughan CW. Carcinoma obstructing the trachea: treatment by laser resection. $N$ Engl Med 1976;294:941.

9 George PIM, Garrett CPO, Goldstraw P, Hetzel MR, Ramsay AD. Resuscitative laser photoresection of a tracheal tumour before elective surgery. Thorax 1986; 41:812-3.

10 Shankar S, George PJM, Hetzel MR, Goldstraw P. Elective resection of tumours involving the trachea and main carina following endoscopic laser therapy. Thorax 1990;45: 493-5.

Thorax 1992;47:1076-77

\section{Multiple cystic pulmonary hamartomas}

M Mushtaq, S P Ward, J T Hutchison, J S Mann

\begin{abstract}
A patient with multiple cystic hamartomas presented with a pneumothorax and later developed a cystic myxomatous vaginal polyp. This and three of the cysts were resected. She remains well 13 years later. Multiple cystic hamartomas are uncommon and may be misdiagnosed as pulmonary metastases.
\end{abstract}

\section{(Thorax 1992;47:1076-1077)}

We report a case of multiple cystic hamartomas in which a cystic myxomatous vaginal polyp later developed.

Case report

A 47 year old housewife presented with breathlessness and cough, which had been preceded by a small haemoptysis. She was otherwise well. Examination showed no abnormality but a chest radiograph showed 12 rounded opacities varying from $5 \mathrm{~mm}$ to several centimetres in diameter, suggesting metastases, though her general appearance belied this diagnosis. Some of the nodules were cystic and contained fluid levels. There was a small left pneumothorax (fig 1). Cytological examination of sputum showed no abnormality and tests for hydatid and rheumatoid disease gave negative results. Because of concern that the opacities might represent pulmonary metastases she underwent left thoracotomy, at which a large cyst was found in the greater fissure arising from the upper lobe, with two further cysts arising from the lower lobe. All three were removed by wedge resection.

Macroscopically, two of the cysts had fleshy tissue hanging from their inner walls; the third was almost solid. Microscopically, the appearances were of pulmonary hamartomas consisting of cystic spaces lined by cuboidal and mucus secreting columnar epithelium. The stroma consisted of mesenchyme (fig 2 ).

Over the subsequent 13 years the hamartomas fluctuated considerably in size. Typically they increased in size until cavities developed, often with fluid levels, and then shrank, though some remained unaltered. Antibiotics were often prescribed because of concern about superinfection. 


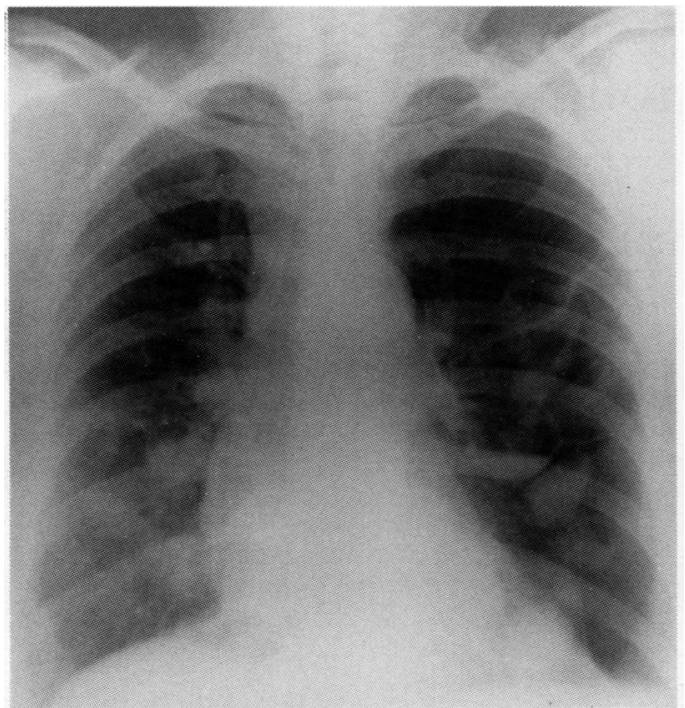

Figure 1 Chest radiograph at presentation showing multiple hamartomas, some of which are cystic, with a left pneumothorax.

In 1985 she developed wheezing. A diagnosis of asthma was made and she improved with a combination of inhaled corticosteroid and bronchodilator treatment. Lung function tests showed a predominantly restrictive defect with mild airflow obstruction and a good response to a bronchodilator. $\mathrm{FEV}_{1}$ was $1 \cdot 19 \mathrm{l}$ and forced vital capacity 1.721 before bronchodilator; they were 1.50 and 1.931 after bronchodilator (predicted $2 \cdot 15$ and $2 \cdot 70 \mathrm{l}$ ). Carbon monoxide transfer factor and transfer coefficient were normal.

In 1980 she had a cystic vaginal polyp removed. Histological examination showed it to be a benign myxoma. The polyp recurred two months later and was treated by wide excision. There has been no further recurrence.

Thirteen years after the diagnosis of cystic hamartomas the patient is breathless with moderate exertion and has mild hypertension but is otherwise well.

\section{Discussion}

A hamartoma is a localised excess or deficiency

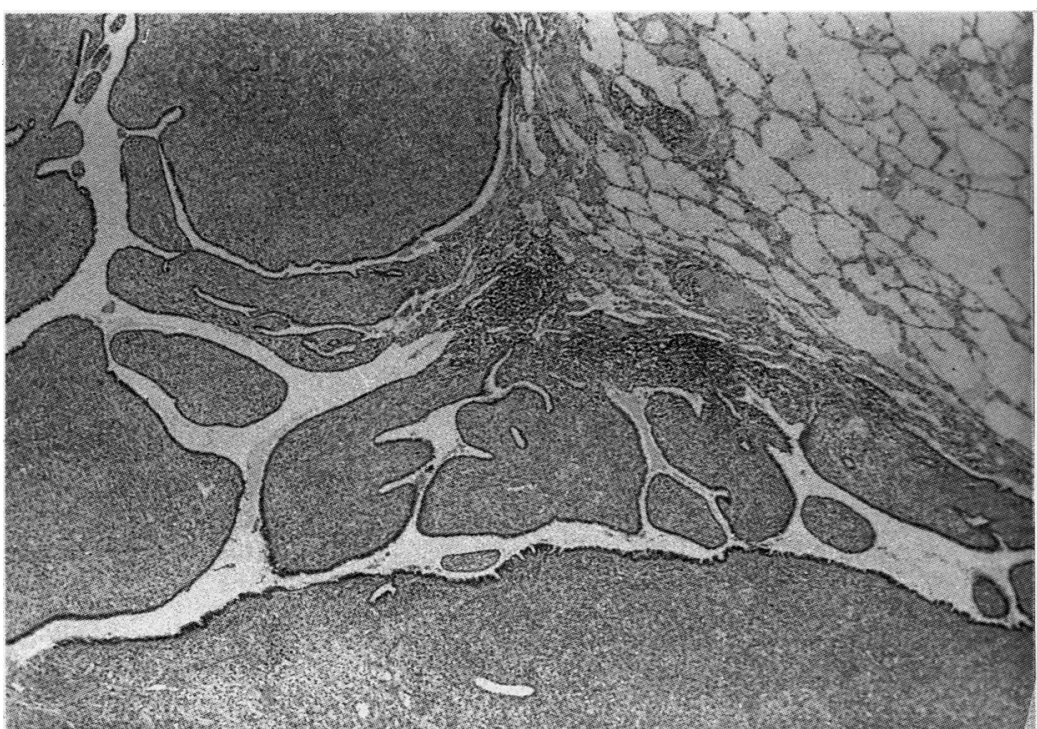

Figure 2 Photomicrograph of a cystic hamartoma showing projections of mesenchymal stroma covered by cuboidal epithelium. of a tissue normally found in an organ and has traditionally been regarded as a developmental abnormality arising from vestiges of fetal tissue. Many, however, now regard hamartomas as benign neoplasms, probably derived from bronchial wall mesenchymal cells. ${ }^{12}$ They are usually solid, well circumscribed nodules, mostly less than $4 \mathrm{~cm}$ in diameter, and about $15 \%$ are calcified.

Cystic pulmonary hamartomas are extremely rare, ${ }^{3-8}$ only 12 cases having been described previously, and we are aware of only four other cases of multiple cystic hamartomas. ${ }^{3}$ As in the present case, the previously reported hamartomas have pursued an indolent course, one patient having survived 28 years before dying from an unrelated cause. The nodules may increase in size and number, occasionally cavitating to become smaller and cystic. Rupture of subpleural cysts may result in a pneumothorax, as in this case, or a haemothorax. Mild haemoptysis may occur and severe haemorrhage from systemic vessels feeding a cyst has been reported. ${ }^{3}$

The association of a myxomatous vaginal polyp with multiple cystic hamartomas in our patient raises the possibility that they were related. In one previous case of multiple cystic pulmonary hamartomas a tumour of the umbilicus was removed. ${ }^{3}$ The tumour comprised primitive mesenchymal cells similar to those in the lung. The authors suggested that this was a metastasis. We believe that the more likely explanation is that multiple cystic hamartomas of the lung are associated with a predisposition to mesenchymal hamartomas elsewhere in the body. An association of pulmonary hamartoma and benign tumours in other organs has been described ${ }^{9}$ and pulmonary hamartomas are a rare manifestation of Cowden's syndrome, a genodermatosis inherited as an autosomal dominant.

The fact that sarcomatous change in cystic hamartomas of the lung in children has been reported lends support to the removal of cystic hamartomas in children. ${ }^{8}$

Multiple cystic hamartomas of the lung are most likely to be confused with metastatic carcinoma. Other differential diagnoses include hydatid disease in endemic areas, rheumatoid nodules, multiple tuberculomas, and-less likely-bronchogenic cysts and bullous emphysema. The condition follows a benign course but may be associated with extrapulmonary myxomatous hamartomas.

1 Bateson EM. Histogenesis of intrapulmonary and endobronchial hamartomas and chondromas (cartilage containing tumours): a hypothesis. J Pathol 1970;101:77-83.

2 Perez-Atayade AR, Seiler MW. Pulmonary hamartoma. An ultrastructural study. Cancer 1984;53:485-92.

3 Mark EJ. Mesenchymal cystic hamartoma of the lung. N Engl J Med 1986;315:1255-9.

4 Adams MJT. "Pulmonary hamartoma" (the cartilaginous type). Thorax 1957;12:268-75

5 Jackson RC, McDonald JR, Clagett OT. Massive cystic pulmonary hamartoma. Report of two cases. $J$ Thorac Surg 1956;31:504-10.

6 Doppman J, Wilson G. Cystic pulmonary hamartoma. Br J Radiol 1965;38:629-31.

7 Demos TC, Armin A, Chandrasekhar AJ, Barron J. Cystic hamartoma of the lung. J Can Ass Radiol 1983;34:149-50.

8 Hedlund GL, Bisset GS, Bove KE. Malignant neoplasms arising in cystic hamartomas of the lung in childhood. Radiology 1989;173:77-9.

9 Gabrail NY, Zara YB. Pulmonary hamartoma syndrome. Chest 1990;97:962-75. 